\title{
Unha experiencia de Aprendizaxe e Servizo para fomentar a aprendizaxe da Xeometría e a colaboración docente
}

\author{
Naya Riveiro, Ma Cristina; Segade Pampín, Mª Elena; Soneira Calvo, Carlos
}

Facultade de Ciencias da Educación, Universidade da Coruña.

\section{RESUMO}

A iniciativa que se presenta é unha experiencia de Aprendizaxe e Servizo realizada durante 0 curso 2017-2018 na materia de Educación Matemática III do terceiro curso do grao en Educación Primaria e que consistiu no establecemento de redes de cooperación e de colaboración entre o profesorado en formación e o profesorado en activo. Esta experiencia de Aprendizaxe e Servizo xorde co obxectivo de fomentar a aprendizaxe da Xeometría e a colaboración docente, para 0 cal 0 alumnado da facultade deseñou, desenvolveu e avaliou nun CEIP dous obradoiros sobre 0 coñecemento e 0 manexo de materiais manipulativos para traballar contidos de Xeometría, orientados á etapa de Educación Primaria, e que formou parte da avaliación da materia de grao. Entre os resultados que se derivan da realización do seminario, destacamos o coñecemento da realidade do mundo educativo, a aprendizaxe necesaria para deseñar e avaliar propostas didácticas e a valoración da importancia da colaboración entre docentes.

PALABRAS CLAVE: Educación Matemática, Educación Primaria, Formación docente, Xeometría, Materiais manipulativos. 


\section{CITA RECOMENDADA:}

Naya Riveiro, M.C.; Segade Pamín, M.E.; Soneira Calvo, C. (2019): Unha experiencia de Aprendizaxe e Servizo para fomentar a aprendizaxe da Xeometría e a colaboración docente. En De la Torre Fernández, E. (ed.) (2019). Contextos universitarios transformadores: construíndo espazos de aprendizaxe. III Xornadas de Innovación Docente. Cufie. Universidade da Coruña. A Coruña (pág. 391-400).

DOI capítulo: https://doi.org/10.17979/spudc.9788497497121.391

DOl libro: https://doi.org/10.17979/spudc.9788497497121

\section{ABSTRACT}

In this work we expose a Service Learning activity that was developed in the academic year 2017-2018 in the subject Mathematics Education III of the third course of the Primary Education Degree. This experience consisted of the establishment of networks of cooperation and collaboration between the Primary teacher students and the active teaching staff. We pretend to promote the learning of geometry and teacher collaboration. Specifically, the Primary teacher students designed, developed, and evaluated, two geometrical workshops, which were given by our students in the Primary School using manipulative materials in order to study geometry concepts. These activities were part of the Primary teacher subject evaluation. Among the results that derive from conducting the workshops, we highlight the knowledge of education's reality, the knowledge needed to design and evaluate didactic activities, and the esteem of the importance of collaboration between teachers.

KEY WORDS: Mathematics Education, Primary Education, Teacher Education, Geometry, Manipulatives. 


\section{INTRODUCIÓN}

A educación universitaria oriéntase cada vez cara a metodoloxías activas que conduzan a novas formas de aprendizaxe que integren a adquisición significativa dos elementos curriculares conxuntamente ao servizo da comunidade (Paez \& Puig, 2013). Neste senso, a aprendizaxe e Servizo (ApS) é un método de ensino que responde á organización de iniciativas que permitan dar resposta a necesidades sociais que contribúan a desenvolver tanto a responsabilidade cívica e o compromiso coa comunidade como as competencias propias da titulación (Puig \& Bär, 2016). A este respecto, é amplamente recoñecido o valor pedagóxico que subxace aos programas de ApS como metodoloxía de aprendizaxe efectiva e estendida (Rodríguez-Gallego, 2013).

Mais para que unha actuación sexa concibida como ApS, identifícanse como elementos indispensables dentro desta metodoloxía de aprendizaxe, que as actividades desenvoltas proporcionen un espazo para a reflexión a partir da experiencia vivida e que permita combinar esta aprendizaxe cos contidos da titulación, de xeito que os obxectivos curriculares e de servizo deben relacionarse e integrarse. Ademais, o alumnado debe ser partícipe das estratexias de traballo colaborativo e de organización das actividades que dean resposta á necesidade social identificada (Palos, 2015).

En base a isto, presentamos a iniciativa de ApS levada a cabo no curso 2017-2018 na que se estableceu unha colaboración entre docentes de institucións educativas de diferentes etapas educativas co dobre obxectivo de, por unha banda, colaborar e axudar na formación docente e, por outra, fomentar o uso de materiais manipulativos para mellorar as habilidades de razoamento xeométrico dos estudantes do grao en Educación Primaria (E.P.).

\section{DESCRICIÓN DA EXPERIENCIA}

A iniciativa que se presenta xurdiu coma unha demanda do profesorado titor do $3^{\circ}$ curso de $\mathrm{E}$. P. do CEIP Galán, froito dunha colaboración previa tamén de Aprendizaxe e Servizo realizada no curso académico 2016-2017. En particular, as docentes indicaron que lles sería de 
utilidade reforzar aspectos relacionados co coñecemento de materiais manipulativos para 0 ensino e aprendizaxe da Xeometría así como coñecer o deseño de recursos didácticos para traballar con estes materiais. Deste xeito, presentouse a oportunidade de establecer redes de cooperación entre profesorado en formación e o profesorado en exercicio, podendo ofrecer así un servizo á comunidade escolar.

En resposta á demanda manifestada polo profesorado do centro de formación no uso de materiais manipulativos para traballar contidos básicos da xeometría e considerando o contido A Xeometría na E. P., recollido na materia de Educación Matemática III do $3^{\circ}$ curso do grao en E. P., aproveitamos a necesidade que atopamos neste centro para prestar un servizo relacionado coa temática da materia e socialmente necesario: axudar, por unha banda, os docentes na súa formación dando a coñecer materiais que poden ser usados nas aulas co seu alumnado e, por outra, axudar 0 alumnado do grao a desenvolver e adquirir capacidades e habilidades de razoamento e visualización xeométrica ademais de fomentar a discusión reflexiva para emitir xuízos fundados e argumentados ante problemas xeométricos sinxelos. Outra cuestión a destacar tamén, foi a importancia de introducir o noso alumnado universitario en aulas reais de E.P. para pór en valor a súa formación matemática.

En particular, segundo as necesidades formuladas, establecemos os seguintes obxectivos de aprendizaxe para a realización da proposta:

- Aprender a deseñar, desenvolver e avaliar pequenos obradoiros educativos en contextos escolares.

- Mellorar as habilidades de razoamento xeométrico.

- Potenciar o coñecemento e uso de materiais manipulativos para favorecer o seu uso no ensino e aprendizaxe da Xeometría nas aulas de E.P.

- Coñecer e analizar o currículo escolar de matemáticas na E. P., en concreto, do bloque de Xeometría da Lei Orgánica para a Mellora da Calidade Educativa.

- A respecto dos obxectivos de servizo á comunidade propostos, estes foron:

- Fomentar a cooperación entre institucións socioeducativas. 
- Contribuír e axudar na formación docente.

- Coñecer o manexo de grupos, fomentando a cooperación e 0 traballo colaborativo entre iguais.

- Valorar a importancia da colaboración entre docentes.

Polo tanto, logo de analizar as necesidades demandadas decidiuse que a mellor resposta sería a realización de pequenos obradoiros onde se presentaban diferentes actividades de razoamento xeométrico onde, para solucionalas, deberían de manexar os distintos materiais manipulativos. Nas diferentes actividades aportáronse os coñecementos que os estudantes do grao en E.P. están adquirindo na materia de Educación Matemática III.

Concretamente, realizáronse dúas visitas ao centro educativo co alumnado universitario onde presentaron dúas propostas educativas con materiais manipulativos como 0 quebracabezas "tangram", o xeoplano e palliñas con limpapipas para a construción de figuras tridimensionais, facendo 0 alumnado protagonista da súa aprendizaxe. As actividades realizáronse en formato de obradoiro, cunha duración de 90 minutos cada unha, e onde cada neno/a tiña asignado un/ha alumno/a universitario/a como orientador de referencia para guialo no desenvolvemento da actividade e axudarlo no manexo do material para que experimenten a súa manipulación e interioricen os conceptos xeométricos correspondentes.

0 proceso de implantación da experiencia realizouse en varias fases ou momentos que se poden consultar na Figura 1.

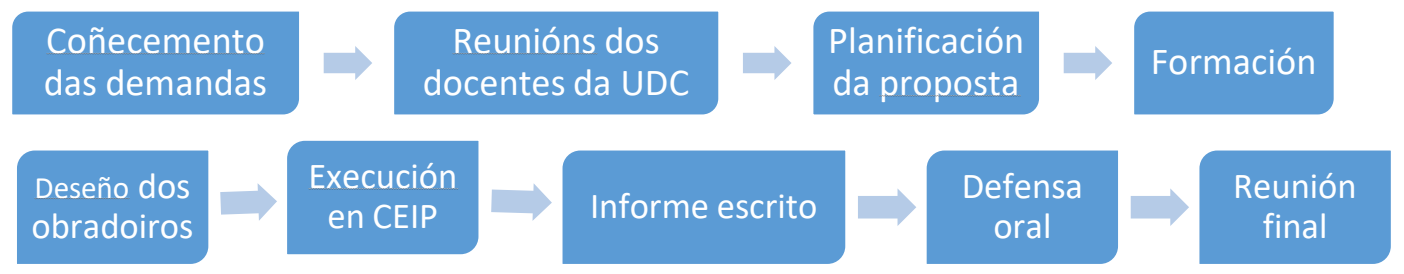

Figura 1. Fases de proceso de implantación do ApS. 
0 primeiro foi coñecer a demanda do centro educativo. A directora, ao coincidir coa coordinadora do proxecto nunhas xornadas de innovación celebradas no Concello de Arteixo, comentoulle a necesidade de que moitos membros do equipo docente do seu centro solicitaban formación na utilización e manexo de materiais. Logo de escoitar as súas demandas, concretouse unha reunión de presentación no centro educativo coas docentes interesadas.

Posteriormente, mantivéronse varias reunións presenciais no centro coas docentes para escoitar as súas demandas concretas e estudar as posibles opcións para propoñer solucións axeitadas ás súas necesidades, obtendo esta información a través dunha pequena entrevista onde se recollían entre outras as seguintes preguntas:

- Anos dando docencia na etapa de Educación Primaria?

- Realizan cursos de formación frecuentemente?

- Coñecen ou usan materiais manipulativos nas aulas?

- 0 manexo do material transmítelle seguranza ou sinte certa inquietude no seu uso na aula?

Ademais, a través do intercambio de varios correos electrónicos coas docentes, recollimos os coñecementos previos sobre contidos de Xeometría que tiñan os alumnos e alumnos de $3^{0}$ curso do CEIP onde se ía realizar o servizo.

Tras as reunións celebradas, propuxéronnos a realización de intervencións na aula cos nosos estudantes, onde a participación do noso alumnado se formulou como proposta de traballo en equipo que formase parte da súa avaliación na materia do grao.

Logo de analizar as demandas manifestadas, os tres docentes da Universidade da Coruña implicados no proxecto reunímonos para poñer en común estas demandas e expoñer ao alumnado a situación para intentar ofrecer unha proposta en común. Decidido o formato da proposta como obradoiro, deseñouse o seguimento da proposta. Isto realizouse de forma secuencial, en varias fases, para favorecer así a súa avaliación. Inicialmente comunicouse co 
centro para transmitirlle a nosa proposta, logo formouse ao alumnado nas horas de docencia da materia, expoñendo os contidos a traballar e as posibles dificultades que podían xurdir.

Deseñáronse as actividades a realizar nas aulas do centro educativo e analizouse 0 material manipulativo, tendo en conta as necesidades expostas polas docentes do centro. Para 0 deseño das actividades propostas no obradoiro, pensáronse como tarefas para realizar nas sesións interactivas da materia Educación Matemática III, onde primeiro foron deseñadas e realizadas polos propios alumnos e alumnas do grao. Deste xeito, detectáronse deficiencias na exposición das tarefas, melloráronse os recursos, e estimouse o tempo necesario para realizar as actividades.

Posteriormente, enviouse 0 deseño das actividades ás docentes das aulas onde iamos impartir os obradoiros, para coñecer a súa impresión, recoller suxestións que puidesen mellorar as tarefas e prever as dificultades que poderían xurdir na aula. Tamén para concretar o número de estudantes que ían recibir o obradoiro para garantir o número necesario de recursos e organizar os materiais manipulativos. A coordinadora do proxecto visitou as aulas para coñecer o espazo no que se ían impartir os obradoiros para favorecer a implantación destes. Así mesmo, asignáronse os diferentes roles que cada alumno ou alumna asumiría: responsable do reparto e recollida do material en cada aula, responsable da presentación xeral das actividades en cada aula, distribución en pequenos grupos etc. Durante a execución dos obradoiros, cada estudante tiña que recoller nun caderno de campo as incidencias, suxestións ou dificultades que acontecían para a súa posterior análise. Ademais, cada docente da universidade estaba nunha aula acompañado da titora do centro educativo para apoiar e analizar as distintas situacións que acontecían no transcurso do obradoiro.

Tras a execución dos obradoiros, o alumnado, organizado en pequenos grupos, realizou informes escritos nos que tiñan que recoller a análise, a avaliación da experiencia así como as dificultades e as propostas de mellora sobre 0 servizo realizado. Tamén tiveron que defender mediante unha exposición oral o traballo, xerando así un espazo de reflexión e debate grupal no que se expuxeron as dificultades organizativas e didácticas que se presentaron e as 
solucións adoptadas para unha futura experiencia; posto que este traballo formou parte da avaliación da materia.

Finalmente, realizouse unha posta en común sobre todo 0 acontecido entre o profesorado da universidade para analizar as dificultades e como mellorar esta experiencia. Así mesmo, comunicáronse ao centro educativo as reflexións finais tanto do alumnado como do profesorado universitario, e mantívose unha reunión coa directora para coñecer as inquedanzas e suxestións que permitisen mellorar a proposta nun futuro.

\section{CONCLUSIÓNS}

A realización da proposta realizouse en varias fases para favorecer o seu seguimento e en cada un dos distintos momentos fóronse recollendo resultados que nos permiten obter conclusións sobre a realización da experiencia ApS.

Precisamente, coa avaliación continua e a elaboración e defensa das memorias, os estudantes indicaron que 0 desenvolvemento desta experiencia serviulles para ver a conexión entre os contidos académicos de Educación Matemática co contexto educativo real, ademais de poder analizar as dificultades tanto de aprendizaxe dos contidos como as derivadas da organización e xestión dunha aula, tendo que aprender a xestionar os imprevistos que poidan acontecer. Manifestan tamén, a importancia que supón este primeiro contacto cun centro escolar para observar a dinámica dunha aula e comprobar as vantaxes que derivan de colaborar con outros docentes, podendo compartir experiencias e coñecer diferentes perspectivas para abordar as cuestións pedagóxicas que se presentan nos procesos de ensino e aprendizaxe.

Igualmente, esta experiencia de ApS deulles a oportunidade de ser conscientes dos procesos que se deben seguir para deseñar un obradoiro, dende a análise das necesidades didácticas, a procura de materiais manipulativos, pasando pola planificación detallada de todas as actividades a realizar até a avaliación final da súa idoneidade.

No relativo á valoración das docentes do CEIP, consideraron esta experiencia de ApS moi positiva coa que tiveron a posibilidade de mellorar a súa formación ao coñecer novas 
propostas didácticas para a área de Xeometría a través dos materiais manipulativos. Ademais, expresaron a súa vontade para proseguir coa colaboración entre ambas institucións educativas ao quedar moi satisfeitos coa iniciativa levada a cabo.

Como aspectos a mellorar, consideramos fundamental planificar con máis tempo algunha das actividades recollidas no obradoiro para analizala con máis detemento, pois nalgún momento da experiencia, para conciliar o horario do centro educativo, das titoras e o dos estudantes da universidade tivemos certas dificultades organizativas, que fixo que outras etapas sufrisen pequenos retrasos na programación do proceso.

Ademais, destaca a importancia deste tipo de colaboración para 0/a docente universitario/a dunha titulación como é o Grado en Educación Primaria, onde estar en contacto coas aulas de Educación Primaria é conveniente para coñecer a súa realidade e aplicar ese coñecemento á docencia universitaria, de xeito que consideramos fundamental fomentar a relación entre a Universidade e os centros escolares dos diferentes niveis educativos.

Polo tanto, con iniciativas como a descrita axúdase a introducir 0 estudante no contexto real do mundo educativo, onde teñen que integrar os contidos académicos da titulación e adaptarse a situacións propias dunha aula contando en todo momento co asesoramento dos docentes tanto da universidade como os mestres en activo. De xeito que coa realización deste ApS tal e como afirma (Campos, 2008) estase contribuíndo a mellorar a formación académica do alumnado e a adquisición de competencias propias da titulación ademais de fortalecer 0 seu compromiso social a través da reflexión sobre a realidade dos procesos educativos.

\section{REFERENCIAS}

Campos Sánchez, L. (2008). El aprendizaje servicio en la universidad como propuesta pedagógica. En M. Martínez Martin (Ed.), Aprendizaje servicio y responsabilidad social de las universidades. Barcelona: Octaedro, pp. 81-92.

Páez Sánchez, M \& Puig Rovira, J.M. (2013). La reflexión en el aprendizaje-servicio. Revista Internacional de Educación para la Justicia Social (RIEJS), 2 (2), pp. 13-32. 
Palos Rodríguez, J. (2015). Los proyectos de ApS siguen etapas bien establecidas y han de estar abiertos a cambios imprevistos. En J.M. Puig Rovira (Ed.), ¿Cómo realizar un proyecto de aprendizaje servicio?: 11 ideas clave. Barcelona: Graó, pp. 103-114.

Puig Rovira, J.M. \& Bär Kwast, B. (2016). Reconocimiento y aprendizaje servicio. RIDAS, Revista Iberoamericana de Aprendizaje y Servicio, 2, pp.139-165.

Rodríguez Gallego, M. R. (2014). El Aprendizaje-Servicio como estrategia metodológica en la Universidad. Revista complutense de educación, 25(1), pp. 95-113. 